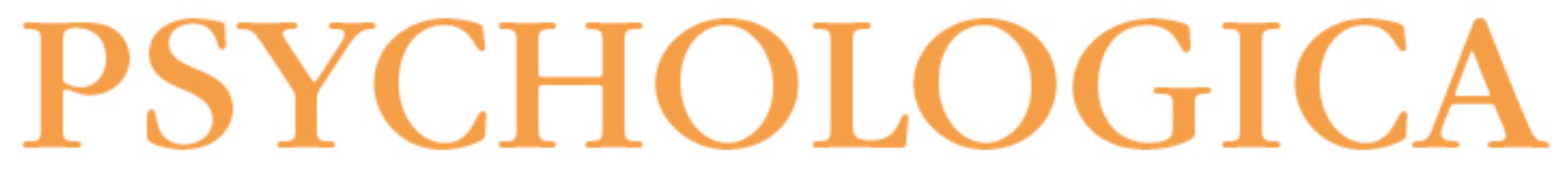

\title{
Avaliação da cultura organizacional: adaptação e validação da versão portuguesa do Denison Organizational Culture Survey
}

\author{
Autor(es): $\quad$ Lousã, Eva Petiz; Gomes, A. Duarte
}

Publicado por: Imprensa da Universidade de Coimbra

URL

persistente: URI:http://hdl.handle.net/10316.2/41450

DOI: DOI:https://doi.org/10.14195/1647-8606_59_2_6

Accessed : $\quad$ 26-Apr-2023 15:52:19

A navegação consulta e descarregamento dos títulos inseridos nas Bibliotecas Digitais UC Digitalis, UC Pombalina e UC Impactum, pressupõem a aceitação plena e sem reservas dos Termos e Condições de Uso destas Bibliotecas Digitais, disponíveis em https://digitalis.uc.pt/pt-pt/termos.

Conforme exposto nos referidos Termos e Condições de Uso, o descarregamento de títulos de acesso restrito requer uma licença válida de autorização devendo o utilizador aceder ao(s) documento(s) a partir de um endereço de IP da instituição detentora da supramencionada licença.

Ao utilizador é apenas permitido o descarregamento para uso pessoal, pelo que o emprego do(s) título(s) descarregado(s) para outro fim, designadamente comercial, carece de autorização do respetivo autor ou editor da obra.

Na medida em que todas as obras da UC Digitalis se encontram protegidas pelo Código do Direito de Autor e Direitos Conexos e demais legislação aplicável, toda a cópia, parcial ou total, deste documento, nos casos em que é legalmente admitida, deverá conter ou fazer-se acompanhar por este aviso.

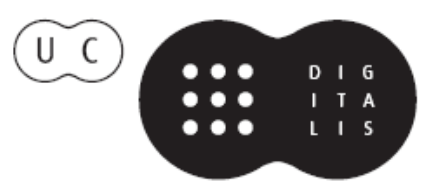


VOLUME

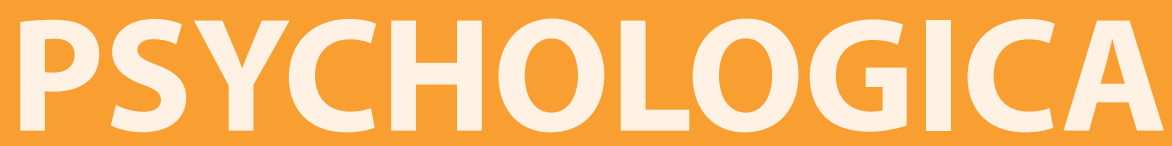

IMPRENSA DA UNIVERSIDADE DE COIMBRA

COIMBRA UNIVERSITY PRESS

FACULDADE DE PSICOLOGIA E DE CIÊNCIAS

DA EDUCAÇÃO DA UNIVERSIDADE DE COIMBRA 


\title{
Avaliação da cultura organizacional: Adaptação e validação da versão portuguesa do Denison Organizational Culture Survey
}

\author{
Eva Petiz Lousã ${ }^{1}$ e A. Duarte Gomes ${ }^{2}$
}

Evaluation of organizational culture: Adaptation and validation of the Portuguese version of the Denison Organizational Culture Survey

\begin{abstract}
This study presents the results of the adaptation and validation of Denison Organizational Culture Survey (2001) in a sample of 905 employees of 102 Portuguese companies. In the study we confirmed the four-dimensional structure and twelve of the questionnaire indicators. Both correlations between different indicators and dimensions as well their internal consistency, showed similar results to those obtained in the original version that justify the adaptation and validation of this instrument for the context of Portuguese companies in the study.
\end{abstract}

Keywords: adaptation; validation; confirmatory factor analysis; reliability

1 Eva Petiz Lousã é doutorada em Psicologia das Organizações, do Trabalho e dos Recursos Humanos pela Universidade de Coimbra e docente do Instituto Politécnico do Porto. É membro do Centro de Investigação em Comunicação e Educação (CICE) no Instituto Superior de Contabilidade e Gestão e professora na Escola Superior de Estudos Industriais e de Gestão, ambas as instituições integradas no referido Instituto Politécnico do Porto. Email: evapetiz@netcabo.pt

2 A. Duarte Gomes é doutorado em Psicologia do Trabalho e das Organizações, professor na Faculdade de Psicologia e de Ciências a Educação da Universidade de Coimbra. Email: duarte.gomes@fpce.uc.pt Artigo recebido a 19-10-2015 e aprovado a 01-07-2016. 


\section{Resumo}

Este estudo apresenta os resultados da adaptação e validação do questionário de Cultura Organizacional (Denison Organizational Culture Survey, 2001). O estudo incidiu sobre uma amostra de 905 colaboradores de 102 empresas Portuguesas. No estudo confirmámos a estrutura de quatro dimensões e de doze indicadores do referido questionário. Tanto as correlações entre os diferentes indicadores e dimensões, como a consistência interna das mesmas, apresentaram resultados semelhantes aos obtidos na versão original que justificam a adaptação e validação deste instrumento para o contexto de empresas portuguesas em estudo.

Palavras-chave: adaptação; validação; análise fatorial confirmatória; fiabilidade

\section{INTRODUÇÃO}

A cultura organizacional constitui um objeto de estudo e uma área de intervenção que continua a despertar o interesse científico e a dar origem a numerosas publicações (e.g., Alvesson, 2002; Ashkanasy, Wilderom, \& Peterson, 2011; Deal \& Kennedy, 1982; Denison, 1990, 1996; Denison, Haaland, \& Goelzer, 2003; Denison, Nieminen, \& Kotrba, 2014; Gomes, 2000, 2004; Hartnell, Ou, \& Kinicki, 2011; Jung et al., 2009; Rebelo \& Gomes, 2011; Sackmann, 2011; Schein, 1990, 1992; Trice \& Beyer, 1993). Décadas de investigação conduziram à emergência de variados modelos explicativos, assim como ao surgimento de diversos instrumentos de medida (Ashkanasy, Wilderom, \& Peterson, 2011; Hartnell, Ou, \& Kinicki, 2011; Jung et al., 2009; Sackmann, 2011; Wilderom, Glunk, \& Maslowsky, 2000). No entanto, como assinalam Denison et al. (2014), o desenvolvimento de instrumentos de medida válidos e fiáveis não tem acompanhado o desenvolvimento teórico entretanto verificado. E, apesar de o número de instrumentos disponíveis não ter parado de crescer (Jung et al., 2009), são várias as questões de natureza metodológica que subsistem no seio da literatura da especialidade (Ashkanasy, Wilderom, \& Peterson, 2011; Sackmann, 2011).

Uma dessas questões tem a ver com o que deve ser avaliado - o que é tácito ou informal, os pressupostos, valores, crenças e atitudes, ou os fenómenos mais observáveis, como os rituais e as normas de comportamento. O modo como os artefactos, os padrões de comportamento e as normas são medidos poderá 
ser diferente do modo adequado para medir atitudes, crenças, valores e pressupostos. De igual modo, as relações de oposição ou as dicotomias geralmente estabelecidas - muitas vezes de forma ingénua, como sublinha Rousseau (1990) - entre, por exemplo, quantitativo e qualitativo, objetivo e subjetivo, superficial e profundo, acessível e inacessível, longe de constituírem um apoio para o debate esclarecido e o progresso dos conhecimentos neste domínio, muitas vezes contribuem para o dificultar. Com efeito e como sublinha Furnham (1997), as dicotomias facilmente conduzem a que um dos polos de uma dada dimensão seja visto como bom e o outro como mau. Além disso, há questões de natureza ética em torno da investigação relacionada com a cultura, e ainda as que se relacionam com a adoção de diferentes níveis de análise. Do mesmo modo, a pluralidade de métodos, associada a uma pluralidade de orientações teóricas, fazem da avaliação e medida um tema pouco pacífico (Ashkanasy, Broadfoot, \& Falkus, 2000; De Witte \& van Muijen, 1999; Gomes, 2004; Rousseau, 1990; Wilderom, Glunk, \& Maslowsky, 2000; Zammuto \& Krakower, 1989).

Em relação aos métodos e sua utilização no contexto da investigação centrada sobre a cultural organizacional, Rousseau (1990) sistematiza muitos dos argumentos aqui mencionados e apresenta uma vasta lista dos instrumentos de medida. Cooke e Szumal (2000) e Ashkanasy, Broadfoot e Falkus (2000) acrescentaram a esta lista outros inventários ou questionários de cultura organizacional. Posteriormente, Jung et al. (2009), numa revisão alargada sobre este tópico, identificaram 70 instrumentos de medida de cultura organizacional e Denison et al. (2014) atualizaram a referida lista. Estes últimos autores, recorrendo aos critérios de validade apresentados por Jung et al. (2009), acrescentaram uma análise aprofundada dos mencionados instrumentos e compararam a sua eficácia. Desta análise mereceu particular realce a versão atualizada e revista do Denison Organizational Culture Survey (DOCS). Este instrumento de medida (Denison, 2001; Denison \& Neale, 1996), que utilizaremos e a que adiante nos referiremos com mais detalhe, tem em vista o estabelecimento de um perfil de cultura organizacional. Com efeito, é relevante poder dispor de instrumentos de medida válidos e fiáveis para que o conhecimento científico sobre uma dada questão de investigação possa progredir e consolidar-se. Para que esse conhecimento possa ser cumulativo e para que sobre essa questão possam ser realizados estudos comparáveis, este é um passo de natureza metodológica que não pode ser ignorado. O presente artigo centra-se sobre a versão portuguesa do instrumento de medida da cultura organizacional DOCS, sua adaptação e validação. E assume, à partida, que não basta traduzir e aplicar um questionário, em particular quando o que está em causa é a avaliação da cultura organizacional, já que esta também implica uma validação intercultural. 


\section{CARACTERIZAÇÃO DO MODELO DE DENISON ORGANIZATIONAL CULTURE}

O questionário sobre cultura organizacional (Denison Organizational Culture - DOC) resultou de um conjunto de estudos empíricos qualitativos e quantitativos, focados nos fatores da cultura organizacional que têm mostrado ter impacto na sua performance e eficácia (Denison, 1984, 1990, 1996, 2001; Denison et al., 2014; Denison \& Mishra, 1995; Denison \& Neale, 1996; Fey \& Denison, 2003). A revisão da literatura, representando ideias de como criar uma cultura eficaz, mostrou ser consistente tanto com as opiniões de gestores como com a literatura da especialidade (Denison, 2001). As dimensões inerentes a este modelo revelaram-se, assim, úteis para o diagnóstico da cultura organizacional (Denison, 2001) e possibilitam a realização de análises comparativas.

No modelo, as crenças e os pressupostos de base ocupam um lugar central, no sentido preconizado por Schein (1992), remetendo para os níveis mais profundos da cultura organizacional. São eles que impulsionam o comportamento e a ação dos indivíduos no contexto organizacional e que possibilitam a existência da ligação que se estabelece entre a organização e os seus membros. Trata-se de um elemento importante para a formação de uma base comum a partir da qual é possível trabalhar em conjunto e comunicar. Por sua vez, os valores e as normas de comportamento fornecem uma orientação e dão origem a expectativas, contribuindo para a criação de uma identidade a nível organizacional. E porque são mais facilmente observáveis do que os pressupostos de base com os quais estão em relação, em momentos de mudança ou face a novos desafios, esses valores e essas normas poderão ser reexaminados.

O modo como a cultura é concebida pelo modelo aqui referido enfatiza ainda a importância dos significados socialmente construídos e tem em vista avaliar a natureza das relações entre os membros da organização (Denison \& Mishra, 1989).

O modelo propõe a existência de quatro dimensões: Envolvimento, Consistência, Adaptabilidade e Missão. A dimensão Envolvimento reflete o quanto os membros da organização estão ou são envolvidos no processo de gestão. A dimensão Consistência reflete a partilha de valores fundamentais, o consenso e os objetivos e metas comuns, entre os membros de todos os níveis da organização, sendo importante para a estabilidade e integração interna. A dimensão Adaptabilidade refere-se à capacidade de as organizações se adaptarem rapidamente às mudanças da sua envolvente, assumindo riscos, aprendendo com os seus erros e acrescentando valor para os seus clientes, vendo aumentadas as suas oportunidades de sobreviver e crescer. A dimensão Missão fornece à organização uma direção estratégica, um propósito ou desígnio, que lhe permite definir os seus objetivos globais, bem como expressar a visão de como será no futuro, proporcionando aos seus membros um percurso apropriado de ação. A identificação dos membros com a missão da organização contribui para que haja 
dedicação a essa organização, a curto e a longo prazo. Cada uma destas quatro dimensões é medida através de três indicadores e cada um destes indicadores comporta cinco itens. Resumidamente, o Envolvimento é medido através dos seguintes indicadores: empowerment (capacidade de iniciativa, responsabilização, poder gerir o próprio trabalho), orientação para a equipa (valorização do trabalho cooperativo em torno de objetivos comuns) e capacidade de desenvolvimento (investimento contínuo no desenvolvimento de competências dos colaboradores). A Consistência é medida a partir dos valores nucleares (valores comuns, identidade e expectativas conjuntas), acordo (capacidade de os membros da organização chegarem a acordo em aspetos críticos e de serem capazes de conciliação face a divergências), coordenação e integração (capacidade de diferentes funções e unidades da organização trabalharem em conjunto para alcançarem metas comuns). A Adaptabilidade é avaliada mediante os seguintes indicadores: criação de mudança (capacidade de a organização interpretar a envolvente, reagir rapidamente a tendências atuais e antecipar mudanças futuras), foco no cliente (grau em que a organização está orientada para a satisfação das necessidades dos seus clientes), aprendizagem organizacional (capacidade de a organização receber, traduzir e interpretar sinais da envolvente e convertê-los em oportunidades para encorajar a inovação, obter conhecimento e desenvolver capacidades). A Missão é medida através dos seguintes indicadores: direção estratégica e intenção (clareza quanto ao propósito da organização e participação empenhada dos membros da organização na direção definida), metas e objetivos (existência de metas e objetivos claros associados à missão, visão e estratégia da organização, proporcionando a todos uma clara orientação para o seu trabalho), visão (capacidade de traçar um futuro atrativo para a organização, devendo essa visão abarcar os valores nucleares e suscitar o comprometimento dos seus membros).

Definidas as quatro dimensões, importa ainda mencionar a relação entre elas e salientar que a importância relativa atribuída a cada uma dessas dimensões pode variar ao longo do ciclo de vida de uma organização. O modelo estabelece um contraste entre estabilidade e flexibilidade, assim como entre foco interno e foco externo. Para a estabilidade contribuem as dimensões Consistência e Missão e para a flexibilidade, Envolvimento e Adaptabilidade; o foco interno tem a ver com Envolvimento e Consistência e o foco externo, com Adaptabilidade e Missão. A complexidade das relações entre as dimensões aqui mencionadas é reconhecida, admitindo-se que possam existir tensões ou flutuações entre elas, designadamente entre Consistência interna e Adaptabilidade externa, do mesmo modo que entre Missão e o Envolvimento. Assim, as organizações que mantêm um foco na prossecução de oportunidades de mercado podem enfrentar problemas ao nível da sua integração interna, como aquelas que se encontram bem integradas e controladas podem ter dificuldades em se focar no cliente. E as organizações que enfatizam a 
missão, e que por isso privilegiam uma comunicação descendente (top-down), muitas vezes encontram dificuldades em pôr em prática o empowerment, por contraste com aquelas que dão maior importância ao envolvimento, e que por isso favorecem as dinâmicas de natureza ascendente (bottom-up), correndo o risco, deste modo, de perderem de vista a missão e a visão. Compatibilizar e enfrentar com eficácia estes desafios não é tarefa fácil e poderá dar origem a diferentes orientações culturais, assim como a diferentes estratégias de as gerir.

Este modelo é, segundo os seus autores, suscetível de ser aplicado a diferentes contextos e áreas geográficas, mantendo as suas características estruturais (Denison et al., 2014). Dada a inexistência de uma versão portuguesa deste questionário e de estudos para a sua validação, consideramos que o questionário de cultura organizacional (DOC) merece ser objeto de estudo e de adaptação ao contexto português atual e às suas organizações empresariais. Nesse sentido, o estudo que aqui apresentamos e que se insere no âmbito de uma investigação mais abrangente (Lousã, 2013), tem por objetivo investigar as características psicométricas do referido questionário, nomeadamente a sua fiabilidade (através da análise da sua consistência interna) e analisar a sua estrutura teórica subjacente, numa amostra de empresas portuguesas.

\section{MÉTODO}

\section{Participantes}

Os dados analisados neste estudo foram recolhidos em 102 empresas portuguesas de base tecnológica e de outros setores de atividade, no período de 2010 e 2011. A antiguidade das empresas varia entre os dois e os 115 anos, sendo a média de cerca de 19 anos (18.98) e o desvio-padrão de 19 anos também (18.97). A amostra é diversificada no que se refere à amplitude de idades das empresas (113 anos), mas no seu conjunto verifica-se um equilíbrio entre as empresas mais jovens e as mais antigas. O número de colaboradores por empresa varia entre dois e 643 pessoas, sendo o número médio de pessoas por empresa de 61.51 e o desvio-padrão de 114.86. Tendo em conta o número de pessoas que a empresa emprega, constatamos que $30.4 \%$ são Microempresas, 38.2\% são Pequenas empresas; $24.5 \%$ são Médias empresas e 5.9\% são Grandes empresas. Estes valores aproximam-se da distribuição do tecido empresarial português, visto que este é predominantemente constituído por micro, pequenas e médias empresas. 
No total participaram 905 colaboradores de ambos os sexos, com uma média de idades de 35 anos (DP =9.1). A maioria dos respondentes tem idades compreendidas entre os 31 e 40 anos (38.2\%), seguindo-se a faixa etária dos 21 anos aos 30 anos (34\%). No que concerne às habilitações académicas constatamos que a grande maioria dos respondentes possui estudos de nível superior, sendo que 39.8\% são licenciados, 9.5\% possuem o mestrado, $2.4 \%$ o bacharelato, $5.3 \%$ o curso de especialização tecnológica e $1 \%$ possui o doutoramento. Dos respondentes que possuem estudos ao nível do secundário ou inferior, verifica-se que $17.5 \%$ possui o $12 .^{\circ}$ ano; $11.7 \%$ tem o $9^{\circ}$ ano de escolaridade, $5.3 \%$ é detentor de um curso profissional ou tecnológico; $5 \%$ possui o $6^{\circ}$ ano de escolaridade e $4.6 \%$ possui o $4^{\circ}$ ano de escolaridade. Relativamente à função que os respondentes desempenham nas respetivas organizações, verificamos que $23.4 \%$ são técnicos, $16.1 \%$ são operários ou operadores, $13.5 \%$ pertencem à direção de departamento, $11.9 \%$ são administrativos, $9.9 \%$ desempenham a função comercial, 8.5\% pertencem à chefia de secção, 3.4\% são estagiários ou aprendizes e 2.5\% desempenham função de direção de topo e, em igual percentagem, a de encarregado. Quanto aos respondentes que mencionaram desempenhar outra função (12.2\%), destacam-se funções como a de planeamento, consultores e designers. A maioria dos respondentes $26.5 \%$ exerce a mesma função há mais de 10 anos, seguindo-se $21.5 \%$ que exerce a função há mais de um ano e menos do que três anos; $17.5 \%$ há mais de três anos e menos do que cinco anos; $15.4 \%$ há mais de cinco anos e menos do que 10 anos; $10.6 \%$ mais de seis meses até um ano e $8.3 \%$ há menos de seis meses. Apenas $1.0 \%$ exerce a mesma função há mais de 10 até 15 anos. Quanto ao departamento em que os respondentes se inserem, a grande maioria (30.9\%) está inserido no departamento de produção, $13.4 \%$ no departamento de investigação e desenvolvimento, $10.2 \%$ no departamento comercial, 7.4\% no departamento administrativo. Os respondentes que referiram que se encontravam inseridos num outro departamento (18.2\%), desempenhavam atividades específicas relacionadas com cada uma das organizações.

\section{Instrumentos}

Foram utilizados dois questionários para recolha de dados, o primeiro dos quais é de caracterização geral, no qual constam dados sociodemográficos relativos à empresa (idade da empresa, número de colaboradores) e relativamente aos participantes (sexo, idade, habilitações literárias), permitindo-nos efetuar a caracterização da amostra. O segundo instrumento é o questionário DOCS (Denison Organizational Culture Survey) que é constituído por 60 itens, 12 indicadores e quatro dimensões. A dimensão Envolvimento (itens 1 a 15) é medida através dos indicadores Empowerment (itens 1 a 5), Orientação para a equipa (itens 6 a 10) e 
Capacidade de desenvolvimento (itens 11 a 15). A dimensão Consistência (itens 16 a 30) é medida através dos indicadores Valores nucleares (itens 16 a 20), Acordo (itens 21 a 25) e Coordenação e integração (itens 26 a 30). A dimensão Adaptabilidade (itens 31 a 45) é medida através dos indicadores Criação de mudança (itens 31 a 35), Foco no cliente (itens 36 a 40) e Aprendizagem organizacional (itens 41 a 45). Por sua vez, a dimensão Missão (itens 46 a 60) é medida através dos indicadores Direção estratégica e intenção (itens 46 a 50), Metas e objetivos (itens 51 a 55) e Visão (itens 56 a 60). A forma de resposta adotada considera uma escala de Likert de cinco pontos, variando de 1 (discordo totalmente) a 5 (concordo totalmente). Oito itens (itens 15, 24, 29, 34, 39, 43, 50, 58) encontram-se numa ordem invertida.

\section{Procedimento}

Inicialmente solicitámos a Denison e colaboradores autorização para utilização deste instrumento, tendo-nos sido enviada uma versão do instrumento em português do Brasil. Esta versão foi por nós adaptada para português de Portugal e comparada com a versão original em língua inglesa, tendo sido de seguida efetuada uma retroversão para garantir a equivalência de conteúdo e de significado (Brislin, 1980). Após ter sido submetido à apreciação de dois peritos (conhecedores da área da cultura organizacional e do inglês) e de se chegar a uma versão de consenso, foi aplicado a um grupo de 10 participantes portugueses. Através da reflexão falada efetuaram-se alguns ajustes ao nível da linguagem, sem que, no entanto, a compreensibilidade dos itens tenha sido afetada.

Posteriormente, as organizações foram contactadas via correio eletrónico, apresentando o estudo e solicitando a colaboração destas. Uma vez obtida a sua aceitação, foram autoadministrados os questionários em cada organização, usando para o efeito meios eletrónicos, sendo disseminados numa amostra de colaboradores pertencentes a diferentes departamentos, níveis hierárquicos e funcionais, representativos da estrutura da organização (cumprindo o critério de que os respondentes deveriam corresponder, pelo menos, a 10\% de colaboradores representativos da estrutura de cada organização).

\section{RESULTADOS}

Realizou-se uma análise preliminar das respostas aos itens do instrumento, analisaram-se as suas características descritivas e passou-se à análise das propriedades psicométricas deste, nomeadamente a sua fiabilidade. Posteriormente, procurou confirmar-se se a estrutura fatorial obtida apoia a estrutura original. 


\section{Análise das respostas aos itens do DOCS}

No que concerne ao estudo dos dados omissos, verificou-se a existência de não respostas em 82 casos, correspondendo a omissos completamente aleatórios, tal como se pode constatar através do teste Little's $M C A R$, que foi não significativo $\left[\chi^{2}(3280)=308.728, \mathrm{p} \geq .05\right]$. Eliminaram-se cinco casos, visto que tinham mais de $10 \%$ de itens não respondidos (Bryman \& Crammer, 1993). Os restantes 77 foram substituídos através do método de estimação de regressão, retendo no final 900 questionários válidos, relativamente a esta escala de resposta. A distribuição dos itens variou entre um valor mínimo de 1 e um máximo de 5 e verificou-se a existência de variabilidade de resposta e de discriminação dos itens. Como se pode observar na Tabela 1, o valor da média de respostas aos itens, variou entre 2.61 e 4.03 e o desvio padrão entre 0.79 e 1.08 . Por sua vez, a análise da sensibilidade dos itens mostrou que estes se situam num intervalo aceitável a uma distribuição aproximadamente normal ( $|\mathrm{Sk}|<3$ e $|\mathrm{Ku}|<8$; Kline, 2011). Em nenhum item se verificou uma acentuada polarização das respostas e na generalidade foi utilizada uma grande amplitude de respostas, sendo que todos os itens foram incluídos na análise.

Tabela 1

Coeficientes Alfa e Estatística Descritiva do Questionário de Cultura

\begin{tabular}{|c|c|c|c|c|c|c|c|}
\hline Dimensão & Indicador & Item & $\mathrm{r}^{\mathrm{a}}$ & Média & DP & Sk & $\mathrm{Ku}$ \\
\hline \multirow{15}{*}{$\begin{array}{l}\text { Envolvimento } \\
\alpha=.90\end{array}$} & \multirow{5}{*}{$\begin{array}{l}\text { Empowerment } \\
\alpha=.80\end{array}$} & 1 & .52 & 3.66 & 0.87 & -0.59 & 0.11 \\
\hline & & 2 & .61 & 3.52 & 0.86 & -0.69 & 0.58 \\
\hline & & 3 & .60 & 3.55 & 0.99 & -0.44 & -0.34 \\
\hline & & 4 & .63 & 3.52 & 0.89 & -0.48 & -0.01 \\
\hline & & 5 & .55 & 3.27 & 0.99 & -0.43 & -0.32 \\
\hline & \multirow{5}{*}{$\begin{array}{l}\text { Orientação para a } \\
\text { equipa } \alpha=.83\end{array}$} & 6 & .61 & 3.59 & 0.98 & -0.71 & 0.16 \\
\hline & & 7 & .69 & 3.73 & 0.88 & -0.61 & 0.19 \\
\hline & & 8 & .67 & 3.55 & 0.96 & -0.59 & -0.11 \\
\hline & & 9 & .59 & 3.78 & 0.85 & -0.63 & 0.39 \\
\hline & & 10 & .59 & 3.48 & 0.90 & -0.56 & 0.10 \\
\hline & \multirow{5}{*}{$\begin{array}{l}\text { Capacidade de } \\
\text { desenvolvimento } \\
\alpha=.68\end{array}$} & 11 & .52 & 3.47 & 0.95 & -0.61 & 0.06 \\
\hline & & 12 & .61 & 3.45 & 0.92 & -0.53 & 0.14 \\
\hline & & 13 & .60 & 3.39 & 1.04 & -0.45 & -0.41 \\
\hline & & 14 & .65 & 3.63 & 0.98 & -0.69 & 0.18 \\
\hline & & ${ }^{*} 15$ & -.07 & 3.31 & 1.01 & -0.19 & -0.58 \\
\hline \multirow{5}{*}{$\begin{array}{l}\text { Consistência } \\
\alpha=.87\end{array}$} & \multirow{5}{*}{$\begin{array}{l}\text { Valores nucleares } \\
\alpha=.68\end{array}$} & 16 & .37 & 3.27 & 1.01 & -0.45 & -0.29 \\
\hline & & 17 & .36 & 3.45 & 0.82 & -0.36 & 0.34 \\
\hline & & 18 & .61 & 3.54 & 0.87 & -0.61 & 0.37 \\
\hline & & 19 & .32 & 3.82 & 0.88 & -0.68 & 0.42 \\
\hline & & 20 & .53 & 3.79 & 0.91 & -0.78 & 0.53 \\
\hline
\end{tabular}




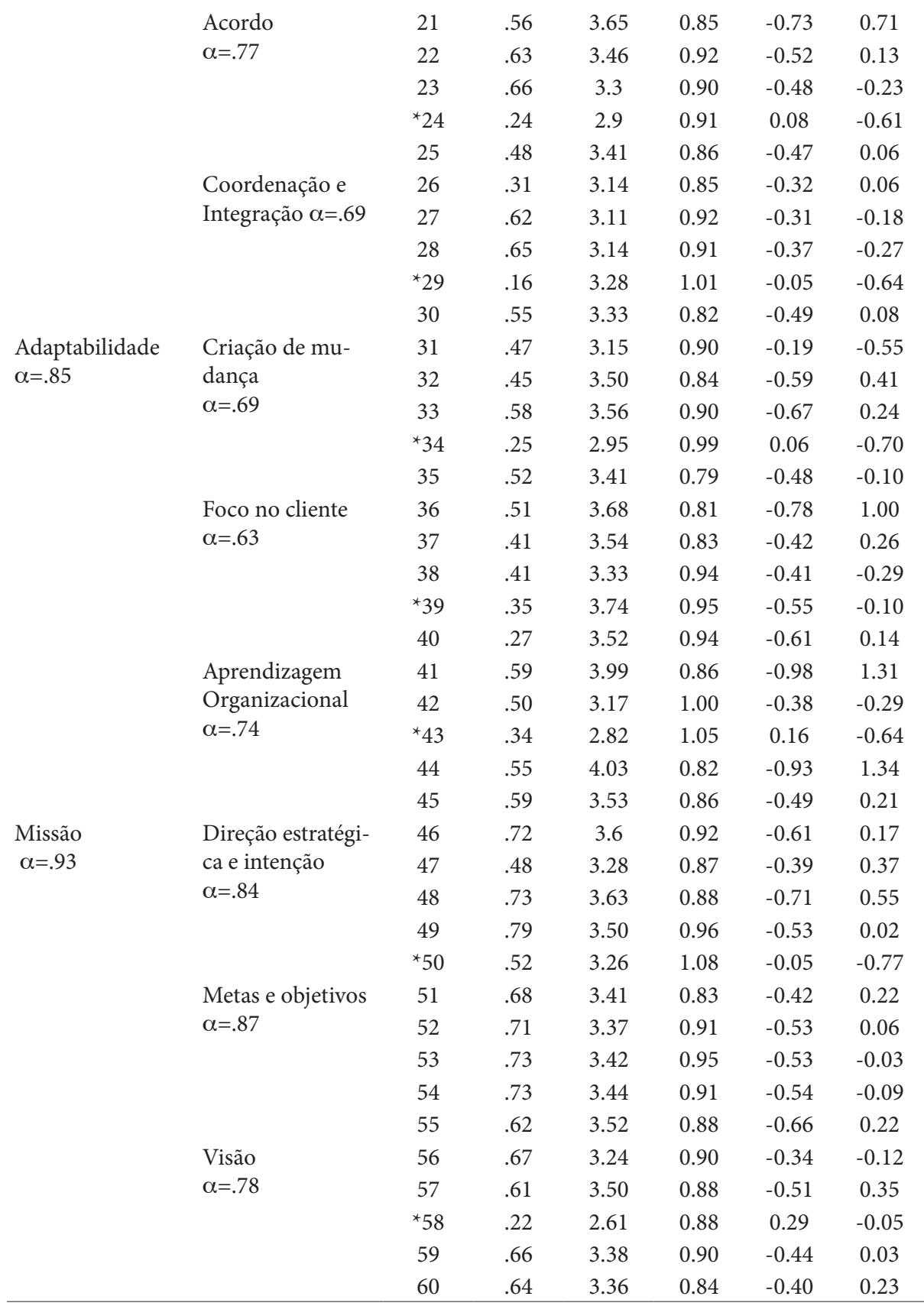

$\mathrm{N}=900 ;{ }^{*}$ item invertido; $\mathrm{DP}=$ Desvio Padrão; $\mathrm{Sk}=$ Assimetria $\mathrm{Ku}=$ Curtose 
Estudo da consistência interna e homogeneidade dos itens do DOCS

Os coeficientes alfa de Cronbach para os doze indicadores variaram entre .63 e .87. Os indicadores 3 ( $A$ informação é amplamente divulgada para que todos possam aceder à informação que precisam quando necessário.), 4 (Todos acreditam que podem exercer um impacto positivo.), 6 (Incentiva-se a cooperação entre diferentes áreas da organização.), 7 (Os colaboradores trabalham como membros de uma equipa.) e 8 (O trabalho é realizado em equipa e não com base em hierarquia) apresentaram valores de coeficientes alfa de Cronbach que variaram entre .63 e .69, indicativo de nível moderado (Hair et al., 2008). Os restantes apresentaram valores superiores a .70, indicativo de um nível de consistência interna adequado (Nunnally, 1978). As correlações item-total ${ }^{3}$ foram superiores a .50 para 41 dos 60 itens da escala. Observou-se o valor de alfa de Cronbach dos respetivos indicadores, caso o item fosse excluído, em cada um dos itens que obtiveram valores baixos nas correlações item-total. Constatou-se que o indicador 8 (Foco no cliente) apresenta um valor mais baixo de consistência interna $\alpha=.63$.

Por sua vez, o item 40 (Incentivamos o contacto direto entre os nossos colaboradores e os clientes.) apresenta um valor de correlação item-total de .27, contudo a sua exclusão não promove uma subida significativa do valor de alfa anteriormente obtido. O item 15, que corresponde à afirmação Os problemas geralmente ocorrem por não termos as competências necessárias para fazer o trabalho, mostrou valor de correlação item-total muito baixo e negativo, -.07. Optou-se pela sua exclusão porque esta promove o alfa de Cronbach do indicador Capacidade de desenvolvimento para o valor de .83 e de .92 para a dimensão Envolvimento. Num outro estudo, Denison et al. (2014) obtiveram um valor baixo de correlação item-total neste item (.22), tendo os autores sugerido que a inclusão deste devesse ser ponderada em estudos posteriores. Optou-se por reter os outros itens, uma vez que o nível de consistência interna dos indicadores é aceitável de .70 (Nunnally, 1978), ou situa-se num valor próximo (.68) e o seu conteúdo é válido e ajusta-se bem ao respetivo indicador.

Após exclusão do item 15, as correlações entre os 12 indicadores variam entre .45 e .79 (média $r=.62$ ), indicando relações moderadas e fortes (ver Tabela 2).

3 Cohen e Holliday (1982; citado em Bryman \& Cramer, 1993) sugerem para a avaliação dos coeficientes de correlação, valores inferiores a .19 como uma correlação muito baixa e entre .20 e .30 como uma correlação baixa. 


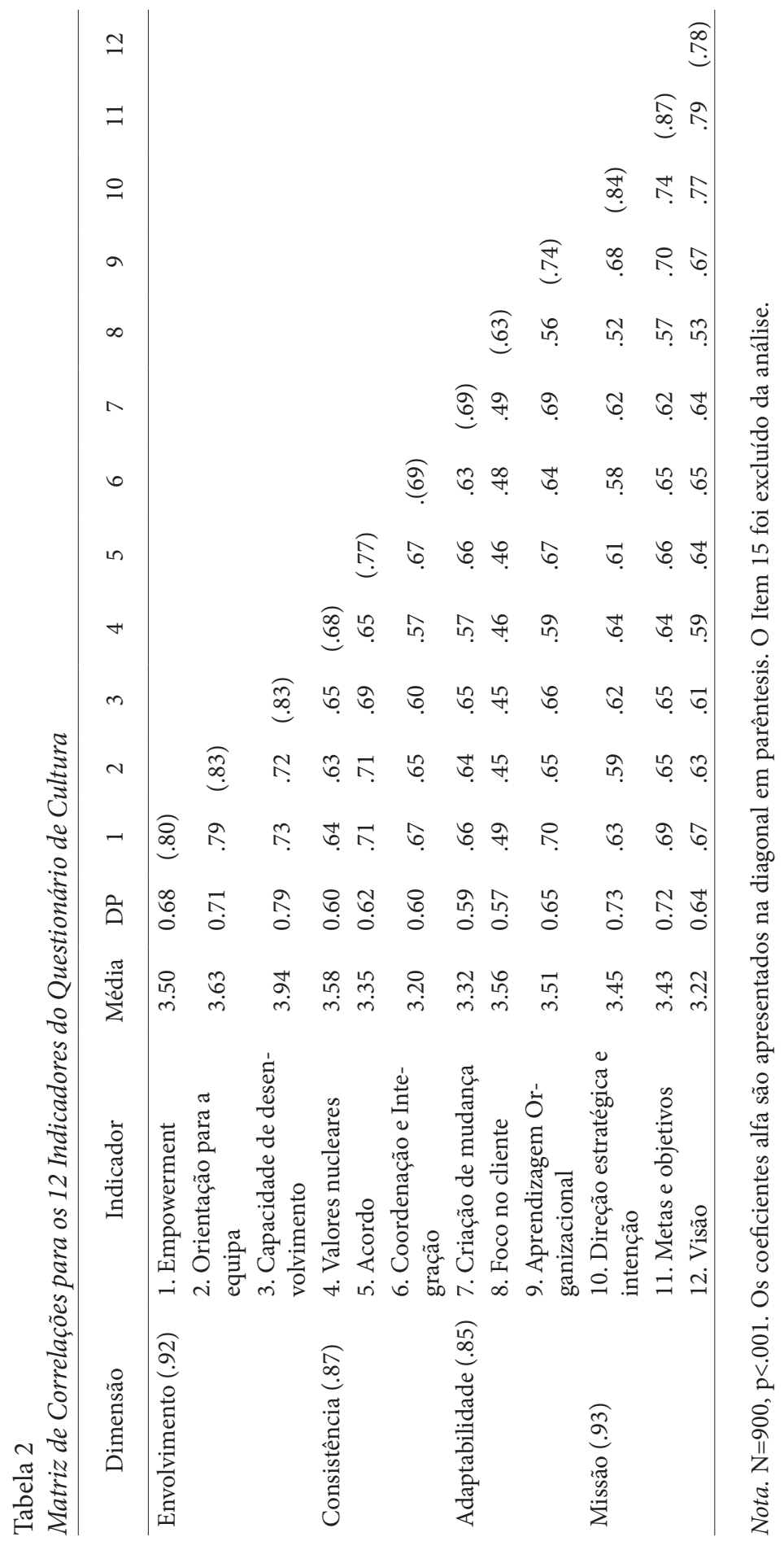




\section{Análise fatorial confirmatória do DOCS}

Procedemos a uma análise fatorial confirmatória usando os 59 itens do questionário da cultura como variáveis observadas, os 12 indicadores como fatores de primeira ordem e as quatro dimensões como fatores de segunda ordem. A análise preliminar para os 900 sujeitos mostrou que o índice de C. R. (Mardia's normalized estimate of multivariate kurtosis) foi de 142, valor superior a cinco, apontado como ponto de corte por Bentler (2005; citado em Byrne, 2010). A análise de outliers multivariados foi efetuada com recurso à Distância Mahalanobis, tendo sido observados 130 casos outliers multivariados com os valores superiores a 90 (Marôco, 2010), os quais foram eliminados. Procedemos, seguidamente, a uma segunda análise confirmatória aos 770 sujeitos, encontrando-se os resultados na Tabela 3. Em termos da análise global do modelo, o teste do Qui-Quadrado revelou um valor estatisticamente significativo $\left[\chi^{2}(1634)=5257.89 ; \mathrm{p}<.001\right]$, o rácio de $\chi^{2} / g .1$ é de 3.22 e um índice de CFI de .85 e o índice de RMSEA o valor de .054, com um intervalo de confiança que varia entre .052 e .055 e cujo teste de aproximação é significativo ( $<$.001). Este modelo hipotético, ainda que tendo alguns valores que se aproximam de um ajustamento aceitável, não se revelou como uma solução satisfatória. Com efeito, se analisarmos os valores de GFI e de AGFI verificámos que estes estão abaixo do mínimo aceitável (Byrne, 2010), tendo valores respetivamente de .78 e .76 .

Tabela 3

Índices de Ajustamento do Modelo ( $n=770)$

\begin{tabular}{|c|c|c|c|c|c|c|c|c|}
\hline Modelo & $\begin{array}{c}\text { Qui- } \\
\text { quadrado }\end{array}$ & gl & $\mathbf{p}$ & RMSEA & GFI & AGFI & CFI & TLI \\
\hline $\begin{array}{c}\text { Modelo } \\
\text { inicial }\end{array}$ & $\begin{array}{c}5257.89 \\
3 \mathrm{gl}=4902 \\
2 \mathrm{gl}=3268\end{array}$ & $\begin{array}{c}1634 \\
\chi 2 / \\
\mathrm{gl}=3.22\end{array}$ & $<.001$ & $\begin{array}{c}.054 \\
\text { IC } 90=.052- \\
.055 \\
\text { pclose }=.002\end{array}$ & .778 & .760 & .851 & .841 \\
\hline $\begin{array}{l}\text { Modelo } \\
\text { (revisão1) }\end{array}$ & $\begin{array}{c}3830.71 \\
3 \mathrm{gl}=2614 \\
2 \mathrm{gl}=3921\end{array}$ & $\begin{array}{c}1307 \\
\chi 2 / \\
\mathrm{gl}=2.93\end{array}$ & $<.001$ & $\begin{array}{c}.050 \\
\text { IC } 90=.048- \\
.052 \\
\text { pclose }=.458\end{array}$ & .823 & .806 & .890 & .884 \\
\hline
\end{tabular}

Nota. RMSEA - Root Mean Square Error of Approximation; GFI - Goodness-of-Fit Index; CFI Comparative Fit Index; AGFI -Adjusted Goodness of Fit; TLI - Tucker-Lewis index.

A análise aos itens 24 (Muitas vezes temos dificuldades para chegar a um acordo em relação a questões chave.), 29 (Trabalhar com alguém de outra área desta organização é como trabalhar com alguém de outra organização.), 34 (As tentativas de criar mudanças são recebidas geralmente com resistência.), 39 (Os interesses do 
cliente são muitas vezes ignorados nas nossas decisões.), 43 (Muitas coisas caem no esquecimento.), 58 (O pensamento de curto prazo muitas vezes obscurece a nossa visão de longo prazo.), mostrou saturações fatoriais estandardizadas inferiores a .45 e $\mathrm{R}^{2}$ inferior <.30. Por sua vez, a análise dos índices de modificação do modelo mostrou um índice mais expressivo para a covariação entre os erros de medida e39 e e50, e29 e e39 e e34 e e58. Tomando em consideração estes dois resultados, decidimos excluir os itens $24,29,34,39,43,58$, por apresentarem índices de baixa saturação e erros de medida correlacionados.

Conduzimos uma nova reespecificação do modelo (revisão 1) e a análise dos índices aponta para um ajustamento aceitável: o teste do Qui-Quadrado revelou um valor estatisticamente significativo $\left[\chi^{2}(169)=3830.71 ; \mathrm{p}<.001\right]$, o rácio de $\chi^{2} / \mathrm{g} .1$. é de 2.93 e um índice de CFI de .89 e o índice de RMSEA o valor de .05, com um intervalo de confiança que varia entre .048 e .052 e cujo teste de aproximação é não significativo $(\mathrm{p}=.458)$. Por sua vez, os valores dos índices de GFI e de AGFI encontram-se dentro do limites de ajustamento aceitável, tendo valores respetivamente de .82 e .81 (Tabela 3). Verificámos que outras correlações de erro não traziam melhorias notórias ao ajustamento, além de que o modelo poderia perder parcimónia. Assim sendo, retivemos este último modelo como estrutura fatorial da cultura a utilizar nesta investigação. Fazendo uma análise ao modelo inicial e ao revisto, constatamos um incremento em todos os índices, sendo as diferenças entre os qui-quadrados das diferentes revisões estatisticamente significativas [Modelo (inicial) e revisão 1: $\left.\Delta \chi^{2}(327)=1427.18 ; \mathrm{p}<.001\right]$.

As Tabelas 4 e 5 apresentam os pesos fatoriais estandardizados de cada um dos 53 itens nos seus respetivos fatores.

Tabela 4 Pesos Fatoriais Estandardizados dos Itens no Fator de $1^{a}$ Ordem e Respetivo Coeficiente de Determinação $\left(R^{2}\right)$

\begin{tabular}{|c|c|c|c|c|c|c|c|}
\hline Item & 1. Empowerment & $\begin{array}{l}\text { 2. Orien- } \\
\text { tação para a } \\
\text { equipa }\end{array}$ & $\begin{array}{l}\text { 3. Capacidade } \\
\text { de desenvolvi- } \\
\text { mento }\end{array}$ & $\begin{array}{l}\text { 4. Valores } \\
\text { nucleares }\end{array}$ & 5. Acordo & $\begin{array}{l}\text { 6. Coorde- } \\
\text { nação e } \\
\text { Integração }\end{array}$ & $\mathbf{R}^{2}$ \\
\hline $\mathrm{CO} 1$ & .59 & & & & & & .35 \\
\hline $\mathrm{CO} 2$ & .70 & & & & & & .49 \\
\hline $\mathrm{CO} 3$ & .73 & & & & & & .54 \\
\hline $\mathrm{CO} 4$ & .70 & & & & & & .49 \\
\hline $\mathrm{CO} 5$ & .68 & & & & & & .46 \\
\hline $\mathrm{CO} 6$ & & .73 & & & & & .53 \\
\hline $\mathrm{CO} 7$ & & .70 & & & & & .49 \\
\hline $\mathrm{CO} 8$ & & .69 & & & & & .48 \\
\hline $\mathrm{CO} 9$ & & .68 & & & & & .47 \\
\hline $\mathrm{CO} 10$ & & .77 & & & & & .59 \\
\hline CO11 & & & .64 & & & & .41 \\
\hline
\end{tabular}




\begin{tabular}{|c|c|c|c|c|}
\hline $\mathrm{CO} 12$ & .76 & & & .57 \\
\hline $\mathrm{CO} 13$ & .76 & & & .58 \\
\hline $\mathrm{CO} 14$ & .79 & & & .62 \\
\hline CO16 & & .65 & & .40 \\
\hline CO17 & & .48 & & .23 \\
\hline $\mathrm{CO} 18$ & & .71 & & .53 \\
\hline CO19 & & .39 & & .15 \\
\hline $\mathrm{CO} 20$ & & .63 & & .36 \\
\hline $\mathrm{CO} 21$ & & & .72 & .53 \\
\hline $\mathrm{CO} 22$ & & & .79 & .62 \\
\hline $\mathrm{CO} 23$ & & & .72 & .51 \\
\hline $\mathrm{CO} 25$ & & & .61 & .38 \\
\hline $\mathrm{CO} 26$ & & & & .18 \\
\hline $\mathrm{CO} 27$ & & & & .49 \\
\hline $\mathrm{CO} 28$ & & & & .48 \\
\hline $\mathrm{CO} 30$ & & & & .63 \\
\hline
\end{tabular}

$\mathrm{N}=770$

Tabela 5

Pesos Fatoriais Estandardizados dos Itens no Fator de $1^{a}$ Ordem e Respetivo Coeficiente de Determinação $\left(R^{2}\right)$

\begin{tabular}{|c|c|c|c|c|c|c|c|}
\hline Item & $\begin{array}{l}\text { 7. Criação de } \\
\text { mudança }\end{array}$ & $\begin{array}{l}\text { 8. Foco } \\
\text { no cliente }\end{array}$ & $\begin{array}{l}\text { 9. Aprendizagem } \\
\text { Organizacional }\end{array}$ & $\begin{array}{l}\text { 10. Direção estra- } \\
\text { tégica e intenção }\end{array}$ & $\begin{array}{c}\text { 11. Metas e } \\
\text { objetivos }\end{array}$ & $\begin{array}{c}12 . \\
\text { Visão }\end{array}$ & $\mathbf{R}^{2}$ \\
\hline $\mathrm{CO} 31$ & .60 & & & & & & .36 \\
\hline $\mathrm{CO} 32$ & .60 & & & & & & .35 \\
\hline $\mathrm{CO} 33$ & .78 & & & & & & .60 \\
\hline $\mathrm{CO} 35$ & .64 & & & & & & .41 \\
\hline $\mathrm{CO} 36$ & & .56 & & & & & .31 \\
\hline $\mathrm{CO} 37$ & & .38 & & & & & .14 \\
\hline $\mathrm{CO} 38$ & & .68 & & & & & .46 \\
\hline $\mathrm{CO} 40$ & & .49 & & & & & .24 \\
\hline $\mathrm{CO} 41$ & & & .70 & & & & .48 \\
\hline $\mathrm{CO} 42$ & & & .61 & & & & .38 \\
\hline $\mathrm{CO} 44$ & & & .68 & & & & .46 \\
\hline $\mathrm{CO} 45$ & & & .74 & & & & .56 \\
\hline $\mathrm{CO} 46$ & & & & .80 & & & .65 \\
\hline $\mathrm{CO} 47$ & & & & .59 & & & .35 \\
\hline $\mathrm{CO} 48$ & & & & .82 & & & .67 \\
\hline $\mathrm{CO} 49$ & & & & .88 & & & .77 \\
\hline $\mathrm{CO} 50$ & & & & .63 & & & .39 \\
\hline $\mathrm{CO} 51$ & & & & & .75 & & .56 \\
\hline $\mathrm{CO} 52$ & & & & & .73 & & .53 \\
\hline $\mathrm{CO} 53$ & & & & & .76 & & .58 \\
\hline $\mathrm{CO} 54$ & & & & & .78 & & .61 \\
\hline $\mathrm{CO} 55$ & & & & & .77 & & .59 \\
\hline $\mathrm{CO} 56$ & & & & & & .79 & .62 \\
\hline
\end{tabular}


$\mathrm{N}=770$

$\mathrm{Na}$ generalidade, os pesos fatoriais estandardizados dos itens variam entre $.60 \mathrm{e}$ .88 , indicando uma variância partilhada considerável dos itens que medem o mesmo conceito subjacente. Alguns dos itens (item 17 Há um estilo característico de gestão e um conjunto distinto de práticas de gestão; 19 Ignorar os valores fundamentais trar-lhe-á problemas.; 26 A nossa maneira de fazer negócios é muito uniforme e previsível.; 37 As nossas decisões são influenciadas diretamente pelo ponto de vista do cliente.; 40 Incentivamos o contacto direto entre os nossos colaboradores e os clientes.) têm valores de saturação fatorial inferiores a .50 e de $\mathrm{R}^{2}$ inferior a .25 . Embora estejam abaixo da referência geralmente adotada, optámos por mantê-los na estrutura e não avançar com mais nenhuma reespecificação do modelo. Na base desta opção, ponderámos razões de ordem estatística e qualitativa, tais como: os valores dos índices apontam para um ajustamento aceitável (Byrne, 2010); os pesos fatoriais dos itens encontram-se acima do .35 e o $\mathrm{R}^{2}$ acima de .15 ; a validade de conteúdo destes itens ajusta-se ao fator na estrutura considerada na versão de origem. Os pesos fatoriais estandardizados dos indicadores no fator de $2^{\text {a }}$ ordem e o seu $\mathrm{R}^{2}$, mantiveram-se, respetivamente, acima de .84 e de .70 (ver Tabela 6). As correlações entre os fatores de segunda ordem do modelo variam entre .85 e .95 , indicando relações fortes.

Tabela 6

Pesos Fatoriais Estandardizados dos Indicadores no Fator de $2^{a}$ Ordem e Respetivo Coeficiente de Determinação $\left(R^{2}\right)$

\begin{tabular}{|c|c|c|c|c|c|}
\hline \multirow[t]{2}{*}{ Indicador } & \multicolumn{4}{|c|}{ Fator } & \multirow[t]{2}{*}{$R^{2}$} \\
\hline & Envolvimento & Consistência & Adaptabilidade & Missão & \\
\hline 1. Empowerment & .94 & & & & .96 \\
\hline 2. Orientação para a equipa & .96 & & & & .91 \\
\hline 3. Capacidade de desenvolvimento & .98 & & & & .88 \\
\hline 4. Valores nucleares & & .95 & & & .90 \\
\hline 5. Acordo & & .96 & & & .92 \\
\hline 6. Coordenação e Integração & & .91 & & & .83 \\
\hline 7. Criação de mudança & & & .94 & & .88 \\
\hline 8. Foco no cliente & & & .84 & & .70 \\
\hline 9. Aprendizagem Organizacional & & & .95 & & .91 \\
\hline 10. Direção estratégica e intenção & & & & .96 & .82 \\
\hline 11. Metas e objetivos & & & & .90 & .92 \\
\hline 12. Visão & & & & .96 & .93 \\
\hline
\end{tabular}

$N=770$. Todas as correlações são significativas ao nível de $p<.01$. 
Por último, comparando os resultados da consistência interna das dimensões e indicadores obtidos neste estudo com os da versão original (Denison et al., 2014), não encontramos grandes discrepâncias (ver Tabela 7).

Tabela 7

Comparação entre a Fiabilidade da Medida do Questionário Original (Denison et al., 2014) e a Versão Adaptada para o Contexto Português no Presente Estudo

\begin{tabular}{lcc}
\multicolumn{1}{c}{ Variáveis } & $\begin{array}{c}\alpha \\
\text { Adaptada }\end{array}$ & $\begin{array}{c}\alpha \\
\text { Original }\end{array}$ \\
\hline Envolvimento $^{\mathrm{a}}$ & .92 & .89 \\
Empowerment $^{\mathrm{b}}$ & .80 & .76 \\
Orientação para a equipa $^{\mathrm{b}}$ & .83 & .82 \\
Capacidade de desenvolvimento $^{\mathrm{b}}$ & .83 & .70 \\
Consistência $^{\mathrm{a}}$ & .88 & .88 \\
Valores nucleares $^{\mathrm{b}}$ & .68 & .71 \\
Acordo $^{\mathrm{b}}$ & .79 & .74 \\
Coordenação e Integração $^{\mathrm{b}}$ & .76 & .78 \\
Adaptabilidade $^{\mathrm{a}}$ & .85 & .87 \\
Criação de mudança $^{\mathrm{b}}$ & .73 & .76 \\
Foco no cliente $^{\mathrm{b}}$ & .63 & .74 \\
${\text { Aprendizagem } \text { organizacional }^{\mathrm{b}}}_{\text {Missão }^{\mathrm{a}}}$ & .77 & .74 \\
Direção estratégica e intenção $^{\mathrm{b}}$ & .94 & .92 \\
Metas e objetivos $^{\mathrm{b}}$ & .84 & .86 \\
Visão $^{\mathrm{b}}$ & .87 & .80 \\
\hline
\end{tabular}

Nota: a) dimensão; b) indicador

\section{DISCUSSÃO}

Poder dispor de um instrumento válido que permita medir e avaliar a cultura organizacional é relevante para a investigação e para a intervenção. O presente estudo incidindo sobre a versão portuguesa do questionário (DOCS) elaborado por Denison et al. (2014) representa uma contribuição nesse sentido. O seu principal objetivo foi adaptar e validar o referido questionário de modo a poder utilizá-lo em investigações ou intervenções levadas a cabo em empresas portuguesas. O reconhecimento de uma pluralidade de métodos e de orientações teóricas em torno da cultura organizacional tem feito da sua avaliação um tema de investigação (Ashkanasy, Broadfoot, \& Falkus, 2000; Gomes, 2004; Wilderom, Glunk, \& Maslowsky, 2000; Zammuto \& Krakower, 1989). Recentes revisões da literatura mostraram progressos no desenvolvimento e 
validação de instrumentos que permitem diagnosticar a cultura organizacional, no qual se inclui o instrumento DOCS (Denison et al., 2014). O recurso a inventários de cultura ou a questionários tem como objetivo principal descrever a cultura ou traçar perfis de cultura, bem como avaliar o seu impacto ou eficácia. A sua utilização visa contribuir para uma resposta a questões como: em que medida determinadas orientações culturais promovem ou facilitam certos resultados?

Os resultados obtidos indicam que o instrumento é válido e que as propriedades psicométricas da versão portuguesa são semelhantes às do questionário homólogo, na sua versão original. A análise fatorial confirmatória e a consistência interna da escala obtiveram resultados satisfatórios. São contudo de salientar alguns aspetos que poderão ser melhorados em adaptações posteriores desta escala.

É de realçar que os resultados obtidos na análise dos 60 itens deste instrumento demonstraram, na generalidade, uma boa consistência interna, tendo-se optado pela exclusão do item 15, devido à baixa correlação item-total. Esta opção foi sustentada pela sugestão dos autores da versão original, que também haviam obtido um valor baixo em estudo anteriormente realizado (Denison et al., 2014). Neste sentido, uma versão inicial da escala ficou composta por 59 itens, sem contudo alterar a configuração dos 12 indicadores da versão original. No presente estudo de validação foram eliminados mais seis itens para se encontrar um ajustamento do modelo aceitável, ficando retidos apenas 53 itens. Após esta supressão, continuou a confirmar-se a estrutura hierárquica de 12 fatores de primeira ordem e de quatro fatores de segunda ordem, devendo ser assinalado que sete dos indicadores ficaram apenas com quatro itens (Capacidade de Desenvolvimento; Acordo; Coordenação e Integração; Criação de Mudança; Foco no Cliente; Aprendizagem Organizacional e Visão). Analisando globalmente os resultados obtidos, pode sustentar-se que estes não apresentam discrepâncias estruturais com o modelo teórico em estudo (Denison et al., 2014). Em suma, consideramos que os resultados obtidos neste estudo relativos à validade da versão portuguesa do instrumento DOCS asseguram o seu bom desempenho psicométrico, tornando-se uma medida multidimensional adequada para avaliação das dimensões de cultura organizacional. A sua aplicação poderá abarcar diferentes contextos, quer de investigação quer de diagnóstico organizacional.

O estudo aqui apresentado não está isento de limitações. Uma dessas limitações decorre da amostragem por conveniência que foi utilizada na investigação, bem como do seu desenho transversal. Estas são limitações a ter em conta numa eventual generalização dos resultados. A necessidade de estudos longitudinais, o aumento do tamanho da amostra, assim como a necessidade de aprofundar a validação intercultural, devem ser consideradas em investigações futuras. Outra questão a aprofundar e a complementar o presente estudo será analisar a validade convergente e discriminante deste instrumento. De igual modo, consideramos que 
no futuro merecerá ser objeto de desenvolvimento a seguinte questão que tem a ver com o modelo teórico subjacente a este questionário, mas que tem também implicações práticas: as quatro dimensões da cultura organizacional aqui destacadas são igualmente importantes em quaisquer contextos ou negócios ou estarão mais associadas a determinados resultados e a certos ciclos de vida das organizações? Em que medida determinadas orientações culturais promovem ou facilitam certos resultados, como a inovação ou aprendizagem organizacional (Rebelo \& Gomes, 2011)? Atender, em simultâneo, às quatro dimensões contempladas pelo modelo poderá, em certas circunstâncias, revelar-se pouco adequado ou vantajoso, ou até inviável. E não sendo possível, quais privilegiar e com que efeitos?

Os autores do modelo apresentado admitem flutuações ou tensões nas relações entre as quatro dimensões. A importância relativa atribuída a cada uma delas numa dada organização poderá estar associada a diferentes resultados considerados desejáveis - aspeto que importa aprofundar e desenvolver. O avanço do conhecimento nesse sentido trará clarificação conceptual, assim como terá implicações práticas e facilitará a intervenção nas organizações.

\section{REFERÊNCIAS}

Alvesson, M. (2002). Understanding organizational culture. London: Sage Publications.

Ashkanasy, N. M., Broadfoot, L., \& Falkus, S. (2000). Questionnaire measures of organizational culture. In N. M. Ashkanasy, C. P. Wilderom, \& M. Peterson (Eds.), Handbook of organizational culture and climate (pp. 131-146). Thousand Oaks, CA: Sage.

Ashkanasy, N., Wilderom, C., \& Peterson, M. (2011). Introduction. In N. Ashkanasy, C. Wilderom, \& M. Peterson (Eds.), The handbook of organizational culture and climate ( $2^{\text {nd }}$ ed., pp. 3-10). Thousand Oaks, CA: Sage.

Bentler, P. M. (2005). EQS 6 Structural equations program manual. Encino, CA: Multivariate Software. Brislin, R. W. (1980). Translation and content analysis of oral and written materials. In H. C. Triandis \& W. W. Lambert (Eds.), Handbook of cross-cultural psychology (Vol. 2, pp. 349-444). Boston, MA: Allyn \& Bacon.

Bryman, A., \& Cramer, D. (1993). Análise de dados em ciências sociais. Introdução às técnicas usando o SPSS ( $2^{\text {nd }}$ ed.). Oeiras: Celta Editora.

Byrne, B. M. (2010). Structural equation modeling with AMOS: Basic concepts, applications and programming ( $2^{\text {nd }}$ ed.). London: Lawrence Erlbaum.

Cohen, L., \& Holliday, M. (1982). Statistics for social scientists. London: Harper and Row.

Cooke, R. A., \& Szumal, J. L. (2000). Using the organizational culture inventory to understand the operating cultures of organizations. In N. M. Ashkanasy, C. P. Wilderom, \& M. F. Peterson (Eds.), Handbook of organizational culture and climate. Thousand Oaks: Sage Publications.

De Witte, K., \& Van Muijen, J. J. (1999). Organizational culture. European Journal of Work and Organizational Psychology, 8(4), 497-502. doi: 10.1080/135943299398122 
Deal, T., Kennedy, A. (1982). Corporate culture: The rites and rituals of corporate life. Massachusetts, Addison-Wesley.

Denison, D. (1984). Bringing corporate culture to the bottom line. Organizational Dynamics, 13(2), 4-22.

Denison, D. (1990). Corporate culture and organizational effectiveness. New York: John Wiley \& Sons.

Denison, D. (1996). What is the difference between organizational culture and organizational climate? A native's point of view on a decade of paradigm wars. Academy of Management Review, 21(3), 619-654. Consultado em https://www.jstor.org/stable/pdf/258997.pdf

Denison, D. (2001). Organizational culture: Can it be a key lever for driving organizational change? In C. Cooper, S. Cartwright, \& P. Earley (Eds.), The international handbook of organizational culture and climate (pp. 347-372). Chichester: John Wiley \& Sons.

Denison, D., Haaland, S., \& Goelzer, P. (2003). Corporate culture and organizational effectiveness: Is there a similar pattern around the world? Advances in Global Leadership, 3, 205-227.

Denison, D., \& Mishra, A. K. (1989). Organizational culture and organizational effectiveness: A theory and some preliminary evidence. Academy of Management Proceedings, 1, 168-172. doi: 10.5465/AMBPP.1989.4980714

Denison, D., \& Mishra, A. K. (1995). Toward a theory of organizational culture and effectiveness. Organization Science, 6(2), 204-223. doi: 10.1287/orsc.6.2.204

Denison, D., \& Neale, W. (1996). Denison organizational culture survey. Ann Arbor, MI: Aviat.

Denison, D., Nieminen, L. \& Kotrba, L. (2014). Diagnosing organizational cultures: A conceptual and empirical review of culture effectiveness surveys. European Journal of Work and Organizational Psychology, 23(1), 145-161. doi: 10.1080/1359432X.2012.713173

Fey, C., \& Denison, D. R. (2003). Organizational culture and effectiveness: Can an American theory be applied in Russia? Organization Science, 14(6), 686-706.

Furnham, A. (1997). The Psychology of behavior at work. Hove: Psychology Press.

Gomes, A. D. (2000). Cultura organizacional: Comunicação e identidade. Coimbra: Quarteto Editora.

Gomes, A. D. (2004). Individus, cultures et organisations. In C. Bonardi, N. Gregori, J-Y. Menard, \& N. Roussiau (Eds.), Psychologie sociale appliquée: Emploi, travail et ressources humaines (pp. 289-309). Paris : Éditions IN PRESS.

Hair, J. F., Anderson, R. E., Tatham, R. L., \& Black, C. W. (2008). Multivariate data analysis ( $7^{\text {th }}$ ed.). Pearson Prentice-Hall.

Hartnell, C. A., Ou, A. Y., \& Kinicki, A. (2011). Organizational culture and organizational effectiveness: A meta-analytic investigation of the competing values framework's theoretical suppositions. Journal of Applied Psychology, 96(4), 677-694. doi: 10.1037/a0021987

Jung, T. S., Scott, T., Davies, H. T., Bower, P., Whalley, D., McNally, R., \& Mannion, R. (2009). Instruments for exploring organizational culture: A review of the literature. Public Administration Review, 69(6), 1087-1096.

Kline, R. B. (2011). Principles and practice of structural equation modeling ( ${ }^{\text {rd }}$ ed.). New York: Guilford Press.

Lousã, E. P. (2013). Liderança empreendedora e cultura de inovação em organizações de base tecnológica e análise comparativa entre setores de atividade. (Tese de doutoramento não publicada). Universidade de Coimbra, Coimbra.

Marôco, J. (2010). Análise de equações estruturais: Fundamentos teóricos, software e aplicações. Pero Pinheiro: ReportNumber.

Nunnally, J. C. (1978). Psychometric theory. New York: McGraw-Hill. 
Rebelo, T., \& Gomes, A. D (2011). The OLC questionnaire: A measure to assess an organization's cultural orientation towards learning. In A. Mesquita (Ed.), Technology for creativity and innovation: Tools, techniques and applications. (pp. 216-236). Hershey, New York: IGI Global.

Rousseau, D. M. (1990). Assessing organizational culture: The case for multiple methods. In Schneider, B. (Eds.), Organizational climate and culture (pp. 153-192). San Francisco, Jossey-Bass.

Sackmann, S. A. (2011). Culture and performance. In N. Ashkanasy, C. Wilderom, \& M. Peterson (Eds.), The handbook of organizational culture and climate ( $2^{\text {nd }}$ ed., pp. 188-224).Thousand Oaks, CA: Sage.

Schein, E. H. (1990). Organizational culture. American Psychologist, 45(2), 109-119.

Schein, E. H. (1992). Organizational culture and leadership. San Francisco, CA: Jossey-Bass.

Trice, H., \& Beyer, J. (1993). The cultures of work organizations. New Jersey: Prentice Hall.

Wilderom, C. P., Glunk, U., \& Maslowski, R. (2000). Organizational culture as a predictor of organizational performance. In N. Ashkanasy, C. Wilderom, \& M. Peterson (Eds.), The handbook of organizational culture and climate ( $2^{\text {nd }}$ ed., pp. 193-209). Thousand Oaks, CA: Sage.

Zammuto, R. F., Krakower, J. Y. (1989). Quantitative and qualitative studies of organizational culture. In R. Woodman \& W. A. Pasmore (Eds.), Research in organizational change and development (Vol. 5, pp. 83-114), Greenwich, Conn, JAI Press. 